\title{
Design and synthesis of a bis-macrocyclic host and guests as building blocks for small molecular knots
}

\author{
Elizabeth A. Margolis, Rebecca J. Keyes, Stephen D. Lockey IV and Edward E. Fenlon ${ }^{*}$
}

\author{
Full Research Paper \\ Address: \\ Department of Chemistry, Franklin \& Marshall College, PO Box 3003, \\ Lancaster, PA 17601, USA \\ Email: \\ Edward E. Fenlon* - edward.fenlon@fandm.edu \\ * Corresponding author \\ Keywords: \\ alkynes; azides; host-guest; macrocycles; molecular knots
}

\author{
Beilstein J. Org. Chem. 2020, 16, 2314-2321. \\ https://doi.org/10.3762/bjoc.16.192 \\ Received: 24 December 2019 \\ Accepted: 02 September 2020 \\ Published: 18 September 2020 \\ Associate Editor: P. J. Skabara \\ (C) 2020 Margolis et al.; licensee Beilstein-Institut. \\ License and terms: see end of document.
}

\begin{abstract}
The thread-link-cut (TLC) approach has previously shown promise as a novel method to synthesize molecular knots. The modular second-generation approach to small trefoil knots described herein involves electrostatic interactions between an electron-rich bismacrocyclic host compound and electron-deficient guests in the threading step. The bis-macrocyclic host was synthesized in eight steps and $6.6 \%$ overall yield. Ammonium and pyridinium guests were synthesized in $4-5$ steps. The TLC knot-forming sequence was carried out and produced a product with the expected molecular weight, but, unfortunately, further characterization did not produce conclusive results regarding the topology of the product.
\end{abstract}

\section{Introduction}

Macrocycles have played a central role in the development of molecular recognition, self-assembled molecular devices, and molecular topology [1-6]. For example, early work by Pedersen on crown ethers [1], Lehn on cryptands [2], and Cram on hemicarcerands [3] demonstrated that preorganized macrocycles have the ability to act as hosts for various guest cations and compounds. Their seminal work was recognized with the 1987 Nobel Prize in Chemistry. More recently, the 2016 Nobel Prize in Chemistry was won by Sauvage, Stoddart, and Feringa for their work on molecular machines [4]. Sauvage [5] and Stoddart [6] extensively used macrocycles in their ground-breaking work on catenanes, rotaxanes, knots, and other topologically novel compounds. Exciting advances in the field of molecular topology continue with novel trefoil knots have been prepared with an all-hydrocarbon example by the Itami group [7] and the synthesis of a single enantiomer by Leigh's group [8]. Complexity has also been achieved with recent work showing that eight-crossing knots [9-11] and a nine-crossing composite knot can be synthesized [12].

Herein the synthesis of a unique bis-macrocyclic host $\mathbf{1}$ is described (Figure 1). Host 1 was designed to be a second-generation building block in the thread-link-cut (TLC) approach to molecular knots [13]. The two 25-atom macrocycles are elec- 


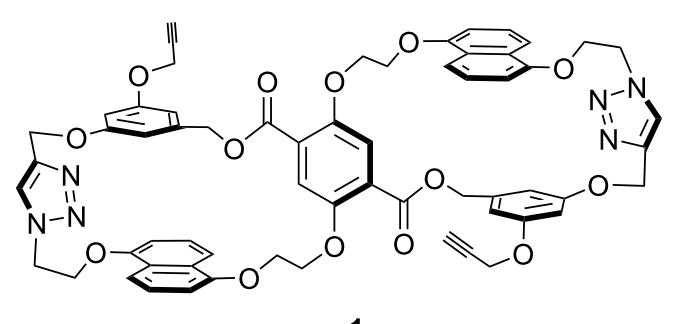

1<smiles>[H][Y18]([H])(CCCCN)Cc1ccc(Oc2ccc(C[NH2+]CCCC[PH3+])cc2)cc1</smiles>

Figure 1: Structures of electron-rich bis-macrocyclic host 1, and electron-poor guests bis(ammonium) 2, and bis(pyridinium) 3 .

tron-rich and complementary to the electron-deficient guests bis(ammonium) 2 and bis(pyridinium) 3 (Figure 1). The electron-rich macrocycles of host $\mathbf{1}$ might also render it useful for other molecular recognition applications.

A principle goal driving our second-generation TLC approach was to test the lower limit on the size of a molecular trefoil knot. In 2008 we surveyed the literature and suggested that a knot of 45-50 backbone atoms was theoretically possible [13]. At that time, the world's smallest knot was an 80 backbone atom trefoil knot-metal complex by the Sauvage group [14].
Shortly thereafter, Hunter's group published the synthesis of a knot-metal complex with 77 backbone atoms (Figure 2a) [15]. More recently, Leigh's group disclosed the synthesis of the current record holder for the smallest knot, which has 76 backbone atoms (Figure 2b) [16]. Since the metal atom template has been removed, the Leigh compound is a true knot in strict topological terms [13,17-20].

The first-generation TLC approach for the synthesis of molecular knots involved a single knot precursor compound that had two macrocycles and two long tails [13,21]. Solvophobic effects a)

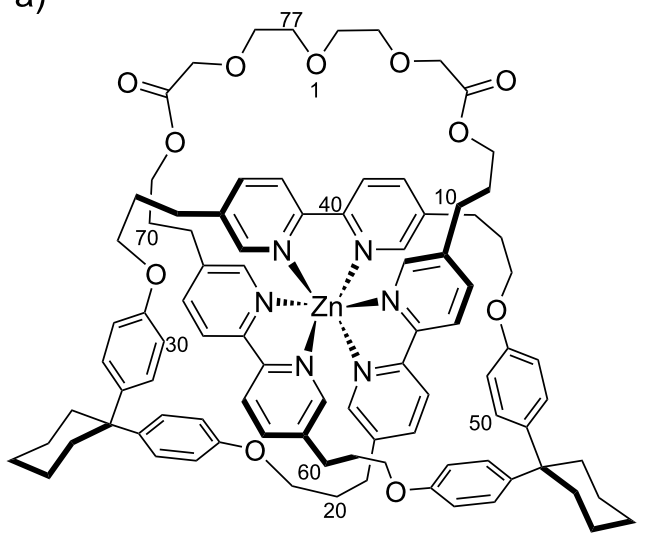

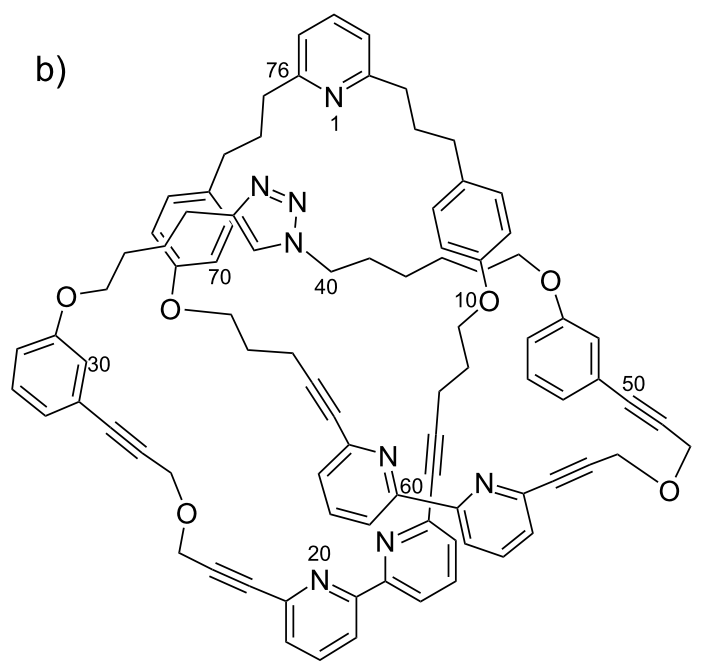

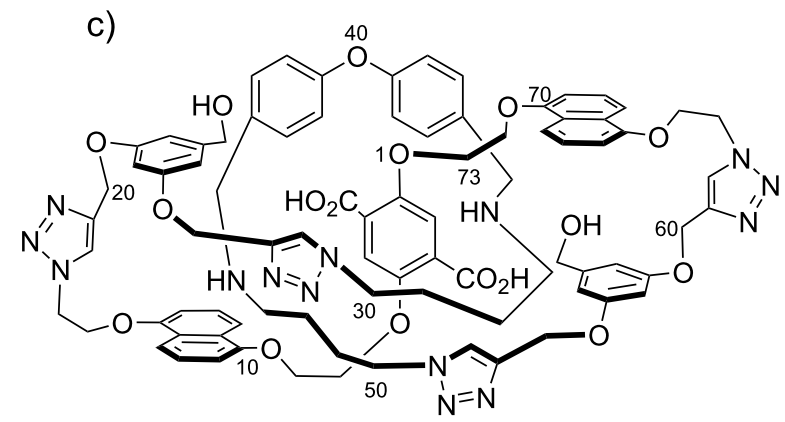

Figure 2: (a) Hunter's 77 backbone-atom trefoil knot-metal complex [9]. (b) The world's smallest knot: Leigh's 76 backbone-atom trefoil [10]. (c) Target 73 backbone-atom trefoil knot of this work using host 1 and guest 2. 
$[22,23]$ were used to promote the tail threading step, ring closing olefin metathesis (RCM) was the linking step, and ester saponification was the cutting step. A potential problem with this approach was that the macrocycles were highly flexible and thus they might adopt a closed conformation hindering the necessary threading step. The flexible tails made the compounds soluble, but also appeared to hinder the formation of crystals suitable for X-ray diffraction to prove the topology of the product.

The second-generation TLC approach to trefoil knots is presented here. It involves the binding of an electron-poor guest ( 2 or 3 ) in an electron-rich host (1) to promote the threading step, an alkyne-azide click cycloaddition as the linking step, and ester saponification as the cutting step [13,21] (Supporting Information File 1). The target trefoil knot using host $\mathbf{1}$ and guest 2 is shown in Figure 2c. The binding event during the double-threading step was modeled after previous literature precedents from the Stoddart [6,24,25], Gibson [26], Loeb [27], and Sanders [28] groups. Furthermore, host 1 was designed to be rigid so that the two macrocycles would maintain an open conformation which is required for the threading step. The approach is modular, such that one host can be paired with multiple guests in order to systematically explore the lower size limits of trefoil knots. For example, if TLC were successful with host 1 and guest 2 , then a 73 backbone-atom trefoil (and the corresponding unknotted macrocycle) would be formed (Figure 3 and Scheme S1 in Supporting Information File 1), whereas host $\mathbf{1}$ and guest $\mathbf{3}$ would lead to a 75 backbone-atom trefoil (and unknotted macrocycle).

\section{Results and Discussion}

The synthesis of bis-macrocyclic host $\mathbf{1}$ began by breaking the symmetry of naphthalene-1,5-diol (4) by alkylation of one of the alcohols with 2-azidoethyl mesylate to yield azide $\mathbf{5}$ in $27 \%$ yield (Scheme 1). Alkylation of 5 with 1,2-dibromoethane provided key intermediate azido-bromide 6 in $60 \%$ yield. This twostep route to $\mathbf{6}$ is efficient, but the $16 \%$ overall yield was lower

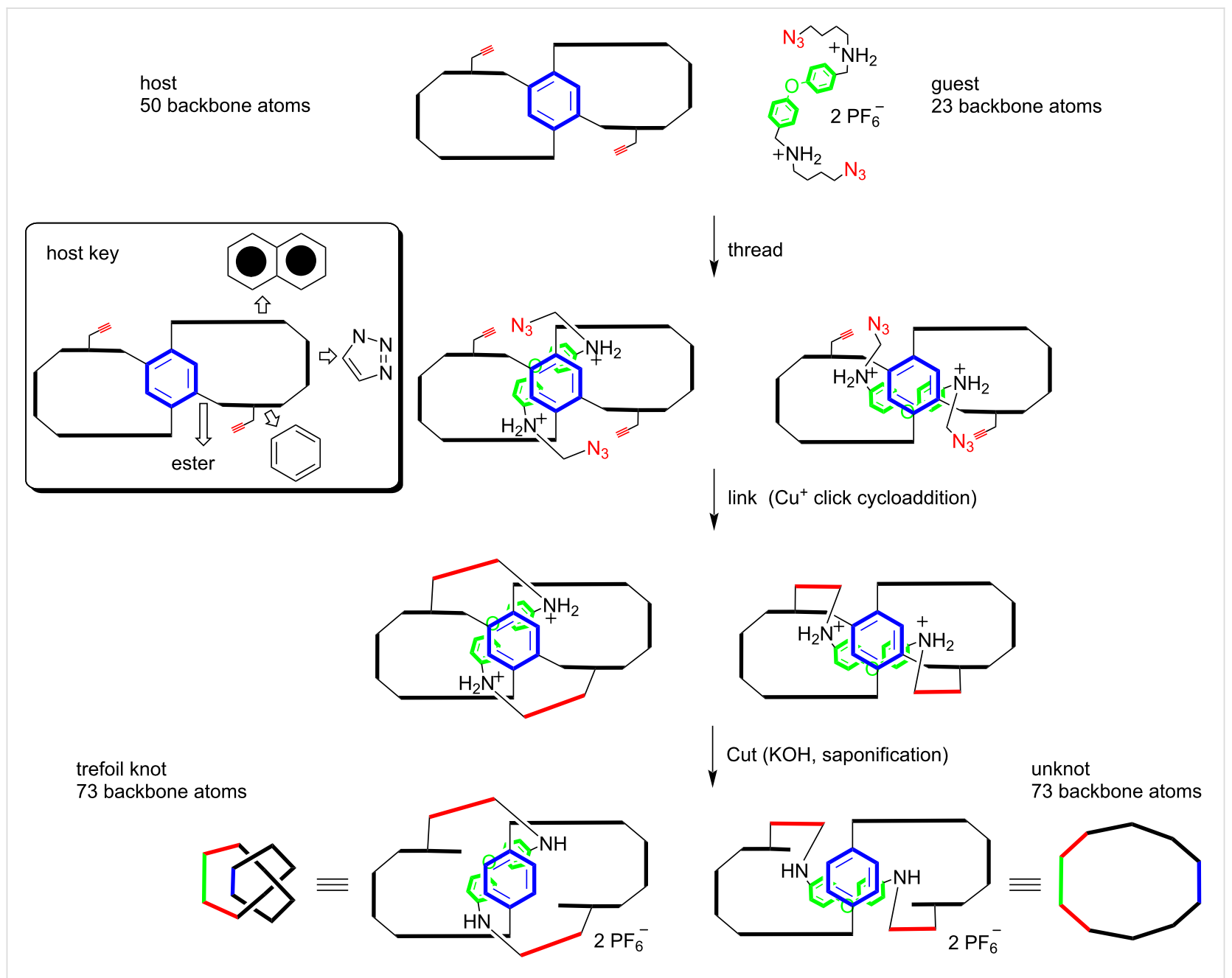

Figure 3: Schematic representation of the second-generation TLC approach to a 73 backbone atom trefoil knot. 


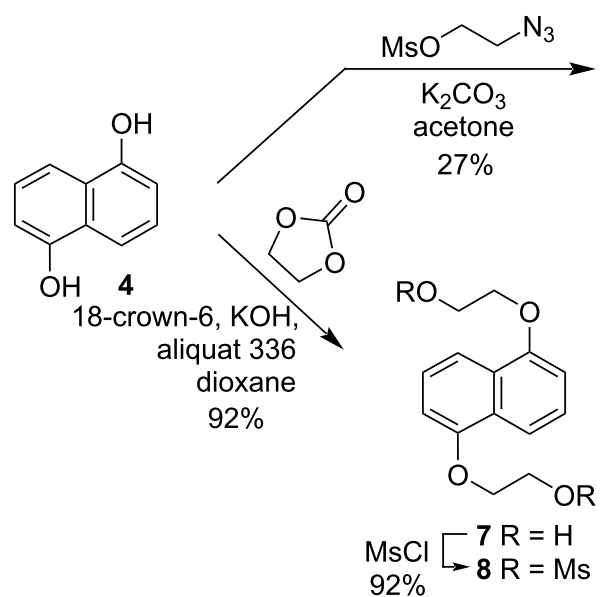

$92 \%$<smiles>N#CCCOc1cccc2c(O)cccc12</smiles>

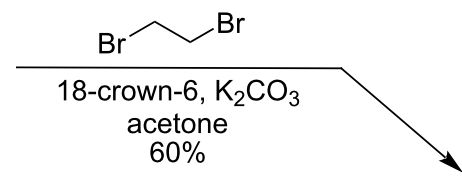<smiles>NCCOc1cccc2c(OCCBr)cccc12</smiles>

Scheme 1: Two routes to azidobromide 6

than desired. An alternate route began by converting diol $\mathbf{4}$ to bis(2-hydroxyethoxy)naphthalene 7 in $92 \%$ yield by reaction with ethylene carbonate using a modified literature procedure (see Supporting Information File 1). Conversion of 7 to bismesylate $\mathbf{8}$ proceeded smoothly in $92 \%$ yield under standard conditions. The symmetry-breaking step in this route involved treatment of $\mathbf{8}$ with one equivalent of sodium azide in DMSO to give azide-mesylate 9 in $35-46 \%$ yield, which is reasonable based on a maximum statistical yield of $50 \%$. Displacement of the mesylate with bromide provided a $94 \%$ yield of 6 . This route to 6 is twice as long as the alternative described above, but it is preferred because the $37 \%$ overall yield is more than twice as high and this route is more amenable to multigram scale reactions.

Azido-bromide 6 can undergo both alkyne-azide click cycloaddition and etherification and the effect of the reaction order on the overall yield was explored next. The click cycloaddition was pursued first and reaction of $\mathbf{6}$ with an excess of known (see Supporting Information File 1) dialkyne $\mathbf{1 0}$ under several of the most common conditions produced triazole $\mathbf{1 1}$ in only modest yields (Scheme 2). The best conditions involved using $\mathrm{Cu}(\mathrm{MeCN})_{4} \mathrm{PF}_{6}$ as the copper(I) source, tris(2-benzimidazolylmethyl)amine as a ligand, and ascorbic acid to provide a $42 \%$<smiles>N#CCOc1cccc2c(OCCBr)cccc12</smiles>

6<smiles>C#CCOc1cc(CO)cc(OCC#C)c1</smiles>

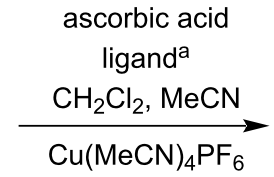

$42 \%$

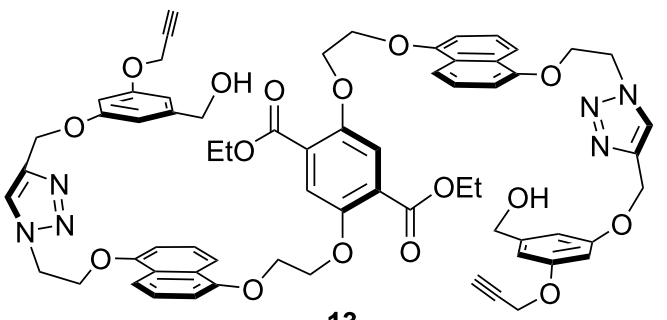

13<smiles>CCOC(=O)c1cc(O)c(C(=O)OCC)cc1O</smiles> 
yield of triazole 11. Alkylation of diethyl 2,5-dihydroxyterephthalate (12) with 11 under standard conditions provided low yields (12-18\%) of the core diester 13, which contains all the atoms of host $\mathbf{1}$. The yields for this route were disappointingly low, so it was hoped that changing the order of these steps would be beneficial.

Alkylation of terephthalate $\mathbf{1 2}$ with azido-bromide $\mathbf{6}$ using cesium carbonate as the base provided high yields (82\%) of core diazide 14 (Scheme 3). Click cycloaddition of $\mathbf{1 4}$ with an excess of dialkyne $\mathbf{1 0}$ also proceeded in high yields (87\%) to give diester 13 which was identical to the material made by the route outlined in Scheme 2. The new route from 6 to 13 proved superior, as the yield for the two-steps improved dramatically from $<8 \%$ to $71 \%$.

Saponification of diester $\mathbf{1 3}$ to diacid $\mathbf{1 5}$ was achieved in moderate-to-good yields (67-90\%) and the ${ }^{1} \mathrm{H}$ NMR spectrum showed the loss of the ethyl ester peaks (Scheme 4). Bis-macrocyclization of $\mathbf{1 5}$ under high-dilution using Shiina's mixed-anhydride method [29] afforded host $\mathbf{1}$ in $28 \%$ yield. As with the analogous first-generation knot-precursor bis-macrocycle [15], host $\mathbf{1}$ was formed as a mixture of meta- and ortho-isomers. It is unknown which of the isomers is the major product, but the isomer ratio is approximately 2:1 based on NMR integrations of several aromatic peaks such as naphthlene signals at 6.7 (major)/6.8 ppm (minor) and the phenyl signals at 6.5 (major)/ $6.6 \mathrm{ppm}$ (minor) and 6.4 (major)/6.3 ppm (minor). This is similar to the first-generation bis-macrocycle which had a $64: 36$ isomer ratio [15]. The macrocycles in host $\mathbf{1}$ are rigid by design (vide supra); however, this rigidity appears to also decrease their solubility. The ${ }^{1} \mathrm{H}$ NMR spectrum was obtained in a dilute DMSO- $d_{6}$ solution and, as expected, several of the aromatic peaks have shifted upfield relative to diacid $\mathbf{1 5}$, because of shielding from nearby aromatic rings. The high-resolution mass spectrometric data and IR spectra also support the successful synthesis of $\mathbf{1}$.

The synthesis of bis(ammonium) guest 2 began with selective displacement of the bromide in 1-bromo-4-chlorobutane (16) with sodium azide to give azide $\mathbf{1 7}$ in $52 \%$ yield (Scheme 5). Treatment of $\mathbf{1 7}$ with potassium phthalimide and catalytic

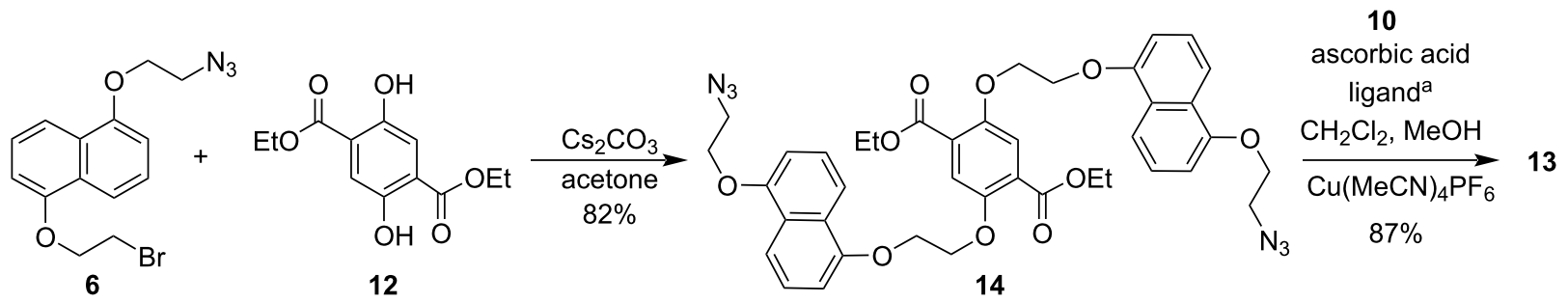

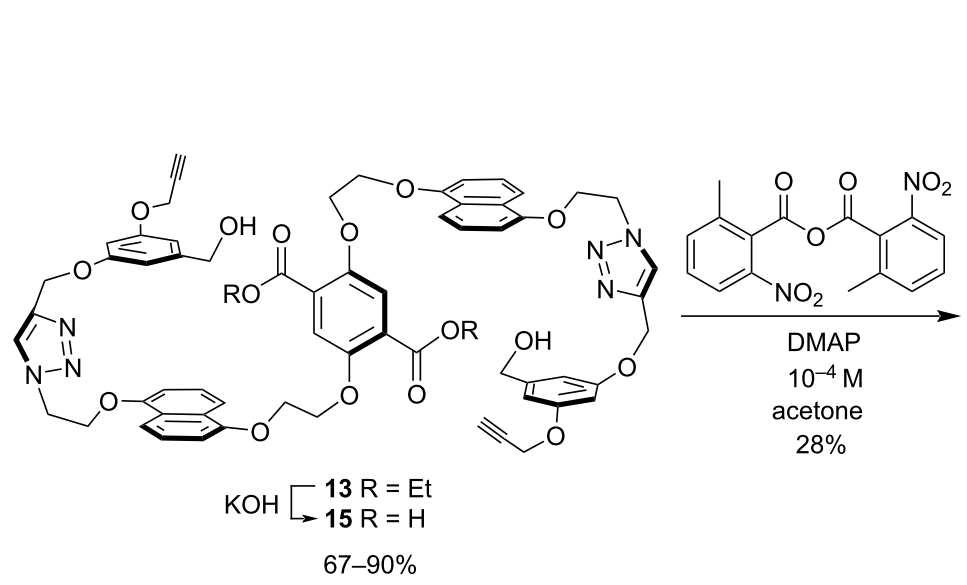

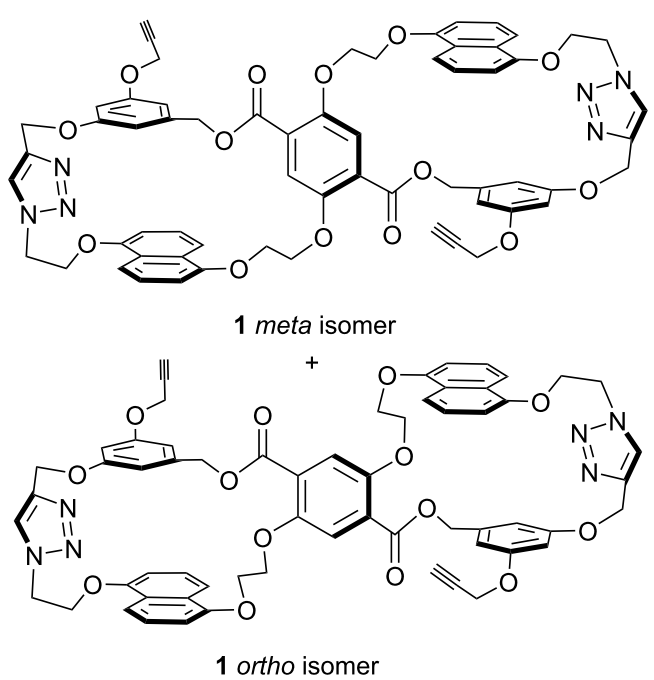




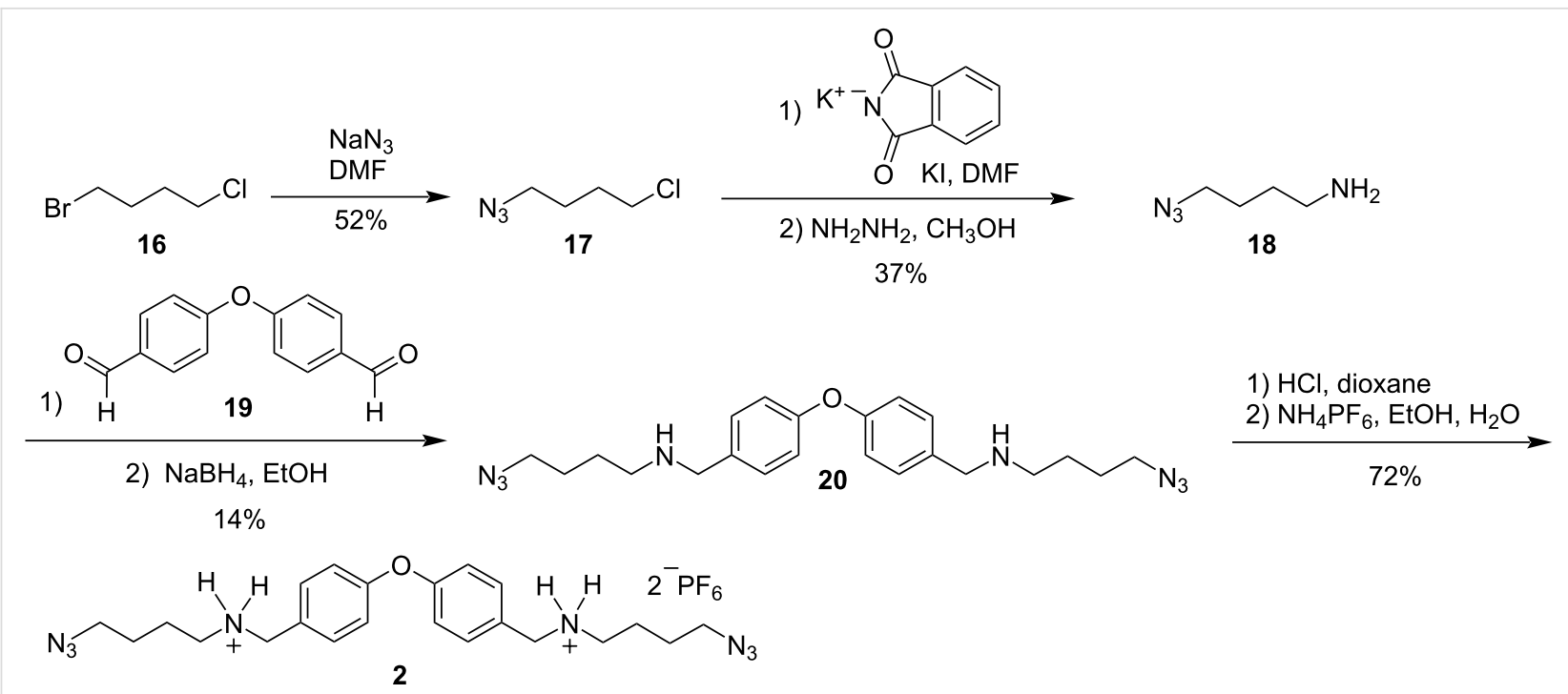

Scheme 5: Synthesis of 23 backbone-atom bis(ammonium) guest 2.

potassium iodide was followed by hydrazine unmasking to give the desired aminoazide $\mathbf{1 8}$ in $37 \%$ over the two steps. Reductive amination of $\mathbf{1 8}$ with dial $\mathbf{1 9}$ provided diazide 20, albeit in low yield (14\%).

Protonation of $\mathbf{2 0}$ with $\mathrm{HCl}$ followed by anion exchange yielded $72 \%$ of the hexafluorophosphate salt of guest 2 . The ${ }^{1} \mathrm{H}$ NMR spectrum supports the ammonium ions of $\mathbf{2}$ as all peaks shifted downfield relative to the chemical shifts in neutral diamine $\mathbf{2 0}$. As expected, the methylene groups closest to the nitrogen atom shifted the most ( $>0.8 \mathrm{ppm}$ for each). The IR spectrum also supports the structure of $\mathbf{2}$, as strong peaks for both an azide asymmetric stretch $\left(v 2099 \mathrm{~cm}^{-1}\right)$ and a $\mathrm{PF}_{6}{ }^{-}$stretching vibration $\left(v 845 \mathrm{~cm}^{-1}\right)$ were observed.

The synthesis of bis(pyridinium) guest 3 started with the conversion of alcohol 21 into the corresponding mesylate followed by substitution with azide to give azidopyridine $\mathbf{2 2}$ in
$82 \%$ yield (Scheme 6). Reaction of 22 with known [18] dibromide 23 , followed by anion exchange, yielded $21 \%$ of the hexafluorophosphate salt of guest 3 . The ${ }^{1} \mathrm{H}$ NMR spectrum supports the pyridinium structure of $\mathbf{3}$ as the aromatic peaks shifted downfield by $0.6-1.4 \mathrm{ppm}$ relative to the chemical shifts in pyridine 22. The IR spectrum supports the structure of $\mathbf{3}$ as strong peaks for both an azide asymmetric stretch ( $v 2102 \mathrm{~cm}^{-1}$ ) and a $\mathrm{PF}_{6}^{-}$stretching vibration $\left(v 835 \mathrm{~cm}^{-1}\right)$ were observed.

To test the threading step, a ${ }^{1} \mathrm{H}$ NMR experiment was conducted. A mixture of $\mathbf{1}$ and $\mathbf{2}$ was dissolved in a 1:1 acetone- $d_{6} /$ DMSO- $d_{6}$ solution. The spectrum of this solution showed upfield shifts of 0.1 to $0.4 \mathrm{ppm}$ for the methylene protons on the guest and smaller downfield shifts of 0.02 to $0.09 \mathrm{ppm}$ for some aromatic resonances on the host. These shifts suggest at least some host-guest complex was formed, even in this competitive polar solvent mixture. The full TLC sequence was tested by<smiles></smiles> 
reacting 1 and $\mathbf{2}$ (1:1 ratio) in a solvent mixture of acetonitrile/ dichloromethane/methanol $(1 \mathrm{~mL} / 1 \mathrm{~mL} / 0.1 \mathrm{~mL})$ with $\left[\left(\mathrm{CH}_{3} \mathrm{CN}\right)_{4} \mathrm{Cu}\right] \mathrm{PF}_{6}$ and ascorbic acid (see Scheme S2 in Supporting Information File 1). After removal of the solvent, the cutting step was performed by heating the crude product with $\mathrm{KOH}$ in a water/THF/ethanol mixture to saponify the esters. The $\mathrm{pH}$ of the mixture was adjusted to neutral by adding $\mathrm{HCl}$ and the resulting precipitate was collected. The IR spectrum of the crude reaction product no longer contained an azide peak, consistent with a successful click cycloaddition. The peaks in the ${ }^{1} \mathrm{H}$ NMR spectrum in DMSO- $d_{6}$ solution at room temperature $\left(\approx 24{ }^{\circ} \mathrm{C}\right)$ were broad, whereas the spectrum at elevated temperature (e.g., $45,90,105^{\circ} \mathrm{C}$ ) had sharper peaks. This effect of temperature on the spectrum is consistent with restricted dynamics of the backbone such as reputation [30] or slow exchange between different conformers; however, both the trefoil knot and the macrocyclic unknot could exhibit this behavior. Two separate triazole peaks were observed (8.19 and $8.38 \mathrm{ppm}$ ), consistent with a new triazole ring being formed. The mass spectrum of the product showed peaks for the expected mass of the TLC product(s) and various cation adducts: (peak mass, assignment, relative intensity): $1563.9 \mathrm{Da}$, $[\mathrm{M}+\mathrm{H}]^{+}, 88 ; 1584.9 \mathrm{Da},[\mathrm{M}+\mathrm{Na}]^{+}, 28 ; 1601.9 \mathrm{Da},[\mathrm{M}+\mathrm{K}]^{+}$, $52 ; 1626.8 \mathrm{Da},[\mathrm{M}+\mathrm{Cu}]^{+}, 42$. It is not surprising that the product would sequester metal cations given its electron-rich macrocyclic nature. Of course, the mass spectral data do not address whether the unknot, trefoil knot, or both were formed (see Scheme S1 in Supporting Information File 1). Repeated attempts to grow X-ray crystals of the product failed. To test for topological chirality, a europium chiral shift reagent was added, but the ${ }^{1} \mathrm{H}$ NMR spectrum was too noisy to discern any peak doubling. Additional experiments, such as the TLC sequence with guest $\mathbf{3}$, were not possible because of a lack of material. Future work will involve making a more soluble host so that NMR and chiral chromatography experiments can be conducted.

\section{Conclusion}

The design of a second-generation thread-link-cut (TLC) approach to molecular knots was described. This differed from the first-generation TLC approach [15] in that the threading event was bimolecular, involving rigid electron-rich bis-macrocyclic host $\mathbf{1}$ and an electron-poor guest molecule ( $\mathbf{2}$ or $\mathbf{3}$ ), rather than unimolecular threading involving solvophobic forces. The flexible and modular approach involving several guests was designed to test the lower size limits on trefoil molecular knots, as the proposed TLC sequence can produce trefoil knots with 73 or 75 backbone atoms. Several synthetic routes to bis-macrocyclic host 1 were explored and the optimized route required eight steps and proceeded with a $6.6 \%$ overall yield. Bis(ammonium) guest 2 was synthesized in five steps with a $1.9 \%$ overall yield and bis(pyridinium) guest 3 was prepared in four steps and 17\% overall yield. The TLC sequence using host $\mathbf{1}$ and guest $\mathbf{2}$ produced a product with the expected molecular weight, but the data were inconclusive on whether this was the unknot, trefoil knot, or a mixture of both.

\section{Supporting Information}

\section{Supporting Information File 1}

Conformations of host 1, TLC knot-forming scheme, experimental procedures and copies of ${ }^{1} \mathrm{H}$ NMR spectra. [https://www.beilstein-journals.org/bjoc/content/ supplementary/1860-5397-16-192-S1.pdf]

\section{Acknowledgements}

We thank Beth Buckwalter for the acquisition of the NMR spectra and Lisa Mertzman for her valuable assistance. We gratefully acknowledge helpful discussions with Sarah Tasker, Scott Van Arman, Dustin Covell, and Scott Brewer. We also thank the peer-review referees for important additions and corrections.

\section{Funding}

This work was supported by Franklin \& Marshall College Hackman and Eyler Funds.

\section{ORCID ${ }^{\circledR} \mathrm{iDs}$}

Stephen D. Lockey IV - https://orcid.org/0000-0002-9264-3198

Edward E. Fenlon - https://orcid.org/0000-0002-6701-8163

\section{References}

1. Pedersen, C. J. Angew. Chem., Int. Ed. Engl. 1988, 27, 1021-1027. doi:10.1002/anie.198810211

2. Lehn, J.-M. Angew. Chem., Int. Ed. Engl. 1988, 27, 89-112. doi:10.1002/anie.198800891

3. Cram, D. J. Angew. Chem., Int. Ed. Engl. 1988, 27, 1009-1020. doi:10.1002/anie.198810093

4. Barnes, J. C.; Mirkin, C. A. Proc. Natl. Acad. Sci. U. S. A. 2017, 114 620-625. doi:10.1073/pnas.1619330114

5. Sauvage, J.-P. Angew. Chem., Int. Ed. 2017, 56, 11080-11093. doi:10.1002/anie.201702992

6. Stoddart, J. F. Angew. Chem., Int. Ed. 2017, 56, 11094-11125. doi:10.1002/anie.201703216

7. Segawa, Y.; Kuwayama, M.; Hijikata, Y.; Fushimi, M.; Nishihara, T.; Pirillo, J.; Shirasaki, J.; Kubota, N.; Itami, K. Science 2019, 365, 272-276. doi:10.1126/science.aav5021

8. Gil-Ramírez, G.; Hoekman, S.; Kitching, M. O.; Leigh, D. A.; Vitorica-Yrezabal, I. J.; Zhang, G. J. Am. Chem. Soc. 2016, 138, 13159-13162. doi:10.1021/jacs.6b08421

9. Danon, J. J.; Krüger, A.; Leigh, D. A.; Lemonnier, J.-F.; Stephens, A. J.; Vitorica-Yrezabal, I. J.; Woltering, S. L. Science 2017, 355, 159-162. doi:10.1126/science.aal1619 
10. Kim, D. H.; Singh, N.; Oh, J.; Kim, E.-H.; Jung, J.; Kim, H.; Chi, K.-W. Angew. Chem., Int. Ed. 2018, 57, 5669-5673. doi:10.1002/anie.201800638

11. Leigh, D. A.; Lemonnier, J.-F.; Woltering, S. L. Angew. Chem., Int. Ed. 2018, 57, 12212-12214. doi:10.1002/anie.201804904

12. Zhang, L.; Stephens, A. J.; Nussbaumer, A. L.; Lemonnier, J.-F.; Jurček, P.; Vitorica-Yrezabal, I. J.; Leigh, D. A. Nat. Chem. 2018, 10, 1083-1088. doi:10.1038/s41557-018-0124-6

13. Fenlon, E. E. Eur. J. Org. Chem. 2008, 5023-5035. doi:10.1002/ejoc.200800578

14. Ditrich-Buchecker, C. O.; Nierengarten, J.-F.; Sauvage, J.-P. Tetrahedron Lett. 1992, 33, 3625-3628. doi:10.1016/s0040-4039(00)92519-x

15. Guo, J.; Mayers, P. C.; Breault, G. A.; Hunter, C. A. Nat. Chem. 2010, 2, 218-222. doi:10.1038/nchem.544

16. Barran, P. E.; Cole, H. L.; Goldup, S. M.; Leigh, D. A.; McGonigal, P. R.; Symes, M. D.; Wu, J.; Zengerle, M. Angew. Chem., Int. Ed. 2011, 50, 12280-12284. doi:10.1002/anie.201105012

17. Walba, D. M. Tetrahedron 1985, 41, 3161-3212. doi:10.1016/s0040-4020(01)96671-2

18. Adams, C. C. The Knot Book; W.H. Freeman and Company: New York, NY, USA, 1994

19. Lukin, O.; Vögtle, F. Angew. Chem., Int. Ed. 2005, 44, 1456-1477. doi:10.1002/anie.200460312

20. Fielden, S. D. P.; Leigh, D. A.; Woltering, S. L. Angew. Chem., Int. Ed. 2017, 56, 11166-11194. doi:10.1002/anie.201702531

21. Fenlon, E. E.; Ito, B. R. Eur. J. Org. Chem. 2008, 3065-3068. doi:10.1002/ejoc.200800387

22. Ponnuswamy, N.; Cougnon, F. B. L.; Clough, J. M.; Pantoş, G. D.; Sanders, J. K. M. Science 2012, 338, 783-785. doi:10.1126/science. 1227032

23. Siegel, J. S. Science 2012, 338, 752-753. doi:10.1126/science. 1230319

24. Chang, T.; Heiss, A. M.; Cantrill, S. J.; Fyfe, M. C. T.; Pease, A. R.; Rowan, S. J.; Stoddart, J. F.; White, A. J. P.; Williams, D. J. Org. Lett 2000, 2, 2947-2950. doi:10.1021/ol0061889

25. Dichtel, W. R.; Miljanić, O. Š.; Spruell, J. M.; Heath, J. R.; Stoddart, J. F. J. Am. Chem. Soc. 2006, 128, 10388-10390. doi:10.1021/ja063127i

26. Bryant, W. S.; Guzei, I. A.; Rheingold, A. L.; Gibson, H. W. Org. Lett. 1999, 1, 47-50. doi:10.1021/ol9905708

27. Loeb, S. J.; Tiburcio, J.; Vella, S. J.; Wisner, J. A. Org. Biomol. Chem. 2006, 4, 667-680. doi:10.1039/b514528g

28. Hamilton, D. G.; Prodi, L.; Feeder, N.; Sanders, J. K. M. J. Chem. Soc., Perkin Trans. 1 1999, 1057-1066. doi:10.1039/a809816f

29. Shiina, I.; Kubota, M.; Oshiumi, H.; Hashizume, M. J. Org. Chem. 2004, 69, 1822-1830. doi:10.1021/j0030367x

30. de Gennes, P.-G. Macromolecules 1984, 17, 703-704. doi:10.1021/ma00134a030

\section{License and Terms}

This is an Open Access article under the terms of the Creative Commons Attribution License (https://creativecommons.org/licenses/by/4.0). Please note that the reuse, redistribution and reproduction in particular requires that the authors and source are credited.

The license is subject to the Beilstein Journal of Organic Chemistry terms and conditions: (https://www.beilstein-journals.org/bjoc)

The definitive version of this article is the electronic one which can be found at: https://doi.org/10.3762/bjoc.16.192 